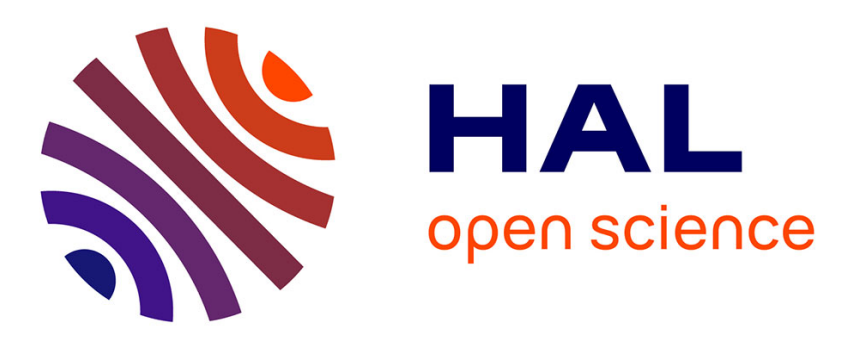

\title{
Comparing Gas-Liquid Segmented and Tube-in-Tube Setups for the Aerobic Dimerization of Desmethoxycarpacine with an Automated Flow Platform
}

Ehu Camille Aka, Eric Wimmer, Elvina Barré, Daniel Cortés-Borda, Tchirioua Ekou, Lynda Ekou, Mireia Rodriguez-Zubiri, Francois-Xavier Felpin

\section{To cite this version:}

Ehu Camille Aka, Eric Wimmer, Elvina Barré, Daniel Cortés-Borda, Tchirioua Ekou, et al.. Comparing Gas-Liquid Segmented and Tube-in-Tube Setups for the Aerobic Dimerization of Desmethoxycarpacine with an Automated Flow Platform. Organic Process Research and Development, 2020, 24 (5), pp.745-751. 10.1021/acs.oprd.9b00525 . hal-03003776

\section{HAL Id: hal-03003776 https://hal.science/hal-03003776}

Submitted on 19 Feb 2021

HAL is a multi-disciplinary open access archive for the deposit and dissemination of scientific research documents, whether they are published or not. The documents may come from teaching and research institutions in France or abroad, or from public or private research centers.
L'archive ouverte pluridisciplinaire $\mathbf{H A L}$, est destinée au dépôt et à la diffusion de documents scientifiques de niveau recherche, publiés ou non, émanant des établissements d'enseignement et de recherche français ou étrangers, des laboratoires publics ou privés. 


\section{Comparing Gas-Liquid Segmented and Tube-in-Tube Setups for the Aerobic Dimerization of Desmethoxycarpacine with an Automated Flow Platform}

Ehu Camille Aka, ${ }^{\ddagger}$ Eric Wimmer, ${ }^{\ddagger}$ Elvina Barré, ${ }^{\ddagger}$ Daniel Cortés-Borda,${ }^{\ddagger}$ Tchirioua Ekou,${ }^{\dagger}$ Lynda Ekou, ${ }^{\dagger}$ Mireia Rodriguez-Zubiri, ${ }^{\dagger}$ and François-Xavier Felpin ${ }^{*}$

¥Université de Nantes, UFR des Sciences et des Techniques, CNRS UMR 6230, CEISAM, 2 rue de la Houssinière, 44322 Nantes Cedex 3, France

† Université Nangui Abrogoua, Laboratoire de Thermodynamique et de Physico-Chimie du Milieu, 02 BP 801 Abidjan 02, Côte d'Ivoire 
a ABSTRACT GRAPHIC

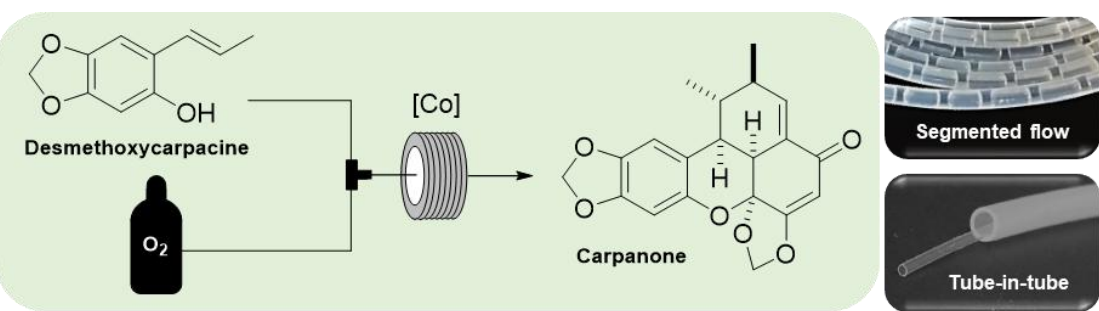




\section{ABSTRACT}

The hazardous nature of molecular oxygen can be mitigated with the use of flow reactors of small size which, in turn, accelerate the gas to liquid mass transfer rate. In this contribution, we describe a reconfigurable automated flow platform integrating an online HPLC monitoring for the cobalt-catalyzed aerobic oxidative dimerization of desmethoxycarpacine $\mathbf{1}$ to carpanone 2 . The flow platform was configured for aerobic oxidation under either a gas-liquid segmented or tube-in-tube strategy. An extensive optimization study concluded that the tubein-tube device was penalized by the use of expensive and fragile Teflon AF-2400 tubing while the gas-liquid segmented setup featured higher yields (62\% vs. $48 \%)$, faster reaction rates ( 5 min vs. 20 minutes) and better robustness.

\section{口 KEYWORDS}

Flow chemistry; Gas/liquid segmented oxidation; Tube-in-tube; Benzoxanthenone

\section{口 INTRODUCTION}

Catalytic aerobic oxidations using molecular oxygen are attractive transformations which often meet the main principles of sustainable chemistry. ${ }^{1-5}$ Benefits of using oxygen are twofold since it is a relatively inexpensive oxidant and can be readily removed from reaction mixtures. Simplified work-up procedures and cleaner syntheses are the main consequences of these features. However, due to its inherent hazardous nature associated to the potential risks of fire and explosion, the handling of oxygen requires the use of stainless-steal autoclaves with a high resistance to pressure in a well ventilated dedicated area. ${ }^{6}$ Another critical point associated with the use of reactive gas, including oxygen, is the low gas to liquid mass transfer rate which strongly affects kinetics, especially upon scaling-up. ${ }^{7}$ Therefore, chemists are often reluctant to develop experimental sequences using oxygen and prefer the use of nongaseous oxygen surrogates which include atom inefficient, toxic and environmentally deleterious stoichiometric metal oxides, hypervalent iodine compounds and hydroperoxides.

Most of the issues associated with the use of oxygen can be addressed by switching from traditional batch synthesis to continuous flow chemistry. ${ }^{8-11}$ The small size of channels in flow reactors mitigates the hazardous nature of oxygen, even under demanding conditions which are not accessible within batch reactors. ${ }^{12-13}$ Also, the delivery of oxygen can be safely regulated and monitored with the use of a mass flow controller. 
Aerobic oxidations in flow have been essentially achieved using two different approaches. The most conventional strategy uses a segmented flow (Taylor flow regime), where liquid slugs are separated by segments of gas. ${ }^{14-22}$ The liquid slugs are subjected to toroidal vertices which increase the interfacial area and improve the gas-liquid mass transfer. ${ }^{23}$ Another approach, allowing efficient gas-liquid contact, consists in the use of a gas-permeable tubing (Teflon AF-2400) inserted inside a larger diameter tubing. ${ }^{24-27}$ The gas can diffuse across the permeable membrane through the formation of microbubbles on the wall of the Teflon AF2400 tubing which are dissolved into the flowing liquid. ${ }^{28}$

We have been interested by the bio-inspired cobalt-catalyzed oxidative dimerization of 2propenyl phenols in flow ${ }^{29-30}$ which led to the formation of natural lignans sharing a benzoxanthenone structure (Figure 1). ${ }^{31-36}$ In our initial studies, we carried out the oxidative dimerization using a stock solution of cobalt catalyst in 1,2-dichloroethane saturated with oxygen. ${ }^{29}$ While the experimental simplicity was the obvious asset of this procedure, we faced critical issues upon scaling-up. First, the experimental setup required to pre-saturate the stock solution with $\mathrm{O}_{2}$ but without any possibility to further introduce $\mathrm{O}_{2}$ in the reactor coil. Such approach required to work at a low concentration of starting material to prevent oxygen to be the limiting reagent, hampering the reaction productivity. The second issue was related to safety concerns associated with the handling of several liters of highly flammable stock solutions. We latter investigated non-gaseous oxygen surrogates using an automated screening platform and we identified $t$-BuOOH as a very efficient oxidant which significantly improved kinetics. ${ }^{30}$ However, the relatively high cost of $t$-BuOOH with respect to oxygen, prompted us to deeply investigate both the segmented flow and tube-in-tube technologies for the oxidative dimerization of desmethoxycarpacine 6 to carpanone $\mathbf{1}$. 
<smiles>[R]CC(=O)O[R6](=O)[O-]</smiles>

Carpanone - 1<smiles>COC(=O)C1=CC(C)[C@]2(C)C[C@@]13c1cc(OC)c(OC)c(OC)c1O[C@@]3(OC)C(OC)=C2OC</smiles>

Polemannone C - 4<smiles>C[C@H]1C=C2C(=O)C=C3OCO[C@]34Oc3cc5c(cc3[C@@H]2[C@@H]14)OCO5</smiles>

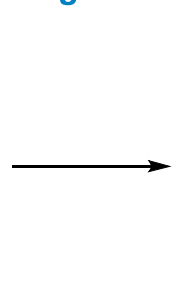

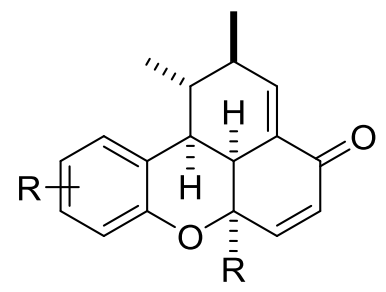

Figure 1. Biomimetic synthesis of naturally-occurring benzoxanthenones.<smiles>COC1=C2OCO[C@]23Oc2c(cc(OC)c(OC)c2OC)[C@@H]2C(=O)C(=O)C(=C[C@H](C)[C@@H]2C)[C@H]13</smiles>

Polemannone A - 2

Sauchinone - 5<smiles>C/C=C/c1cc2c(cc1O)OCO2</smiles><smiles>COC1=C2OCOC23Oc2c(cc4c(c2OC)OCO4)[C@@H]2[C@@H](C)[C@@H](C)C=C(C(=O)C1=O)[C@H]23</smiles>

Polemannone B - 3
Desmethoxycarpacine - 6

\section{口 RESULTS AND DISCUSSION}

An automated flow platform including the tube-in-tube technology was set up to screen a variety of experimental conditions on the $\mu$ mol scale (Figure 2). 
<smiles>C/C=C/c1cc2c(cc1O)OCO2</smiles>

p-Xylene 7, [1 M]

[Co]-8a-d, [7.5 x 10-4 M]

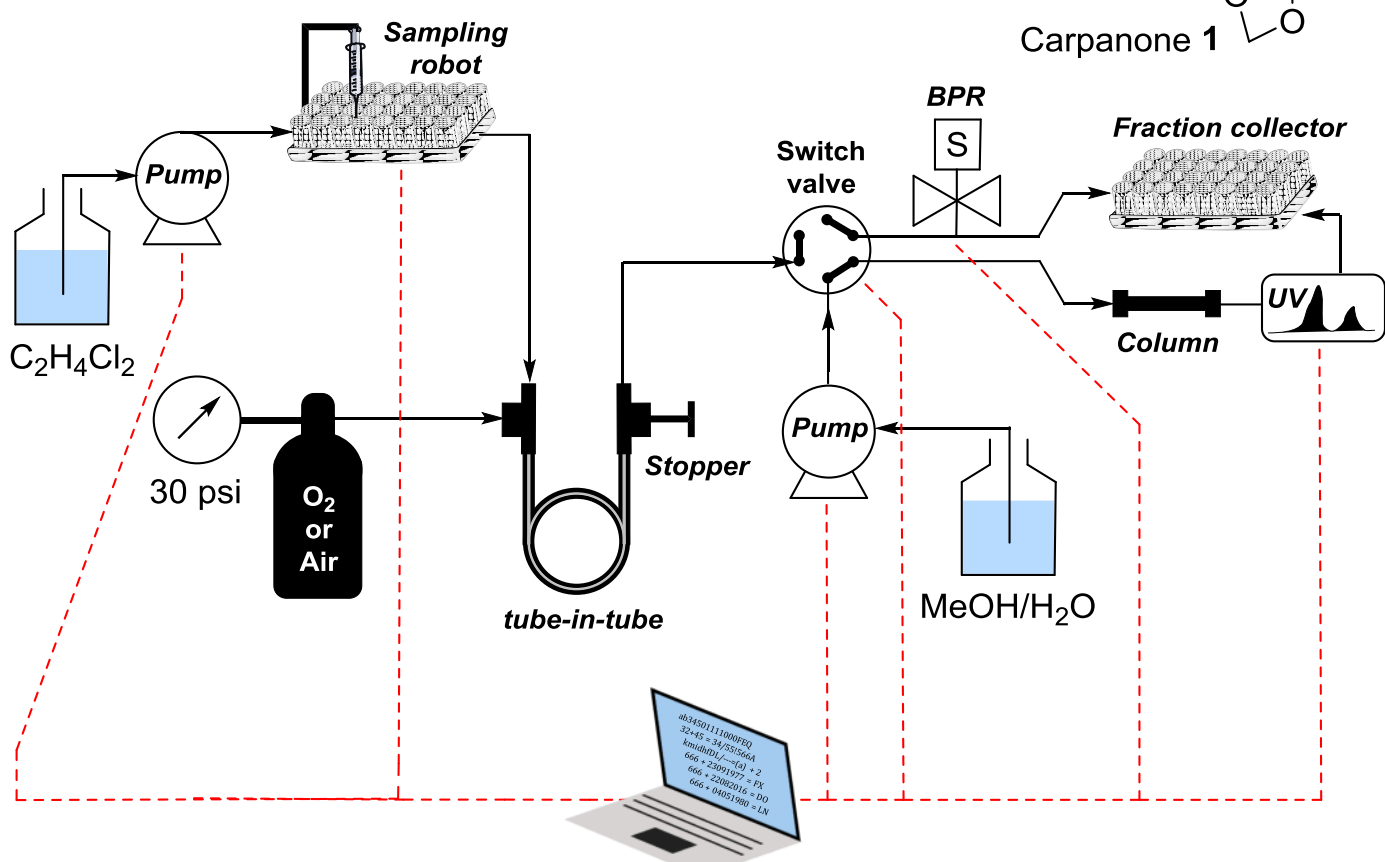

Matlab control

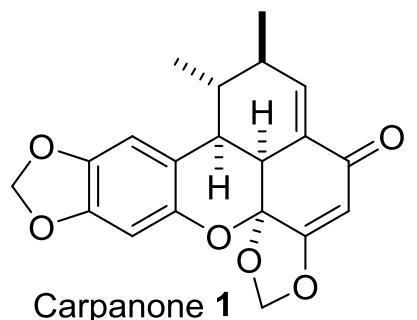

Fraction collector 
$8 \mathbf{a}\left(7.5 \times 10^{-4} \mathrm{M}\right)$ in the reactor which consisted of a Teflon AF-2400 tubing $(0.96 \mathrm{~mL}, 1.9 \mathrm{~m}$, $1 \mathrm{~mm}$ o.d., $0.8 \mathrm{~mm}$ i.d.) inserted within a 1/8" ETFE tube $(7.1 \mathrm{~mL}, 1.9 \mathrm{~m}, 3.2 \mathrm{~mm}$ o.d., 2.4 mm i.d.) through T-shaped junctions (Figure 3).

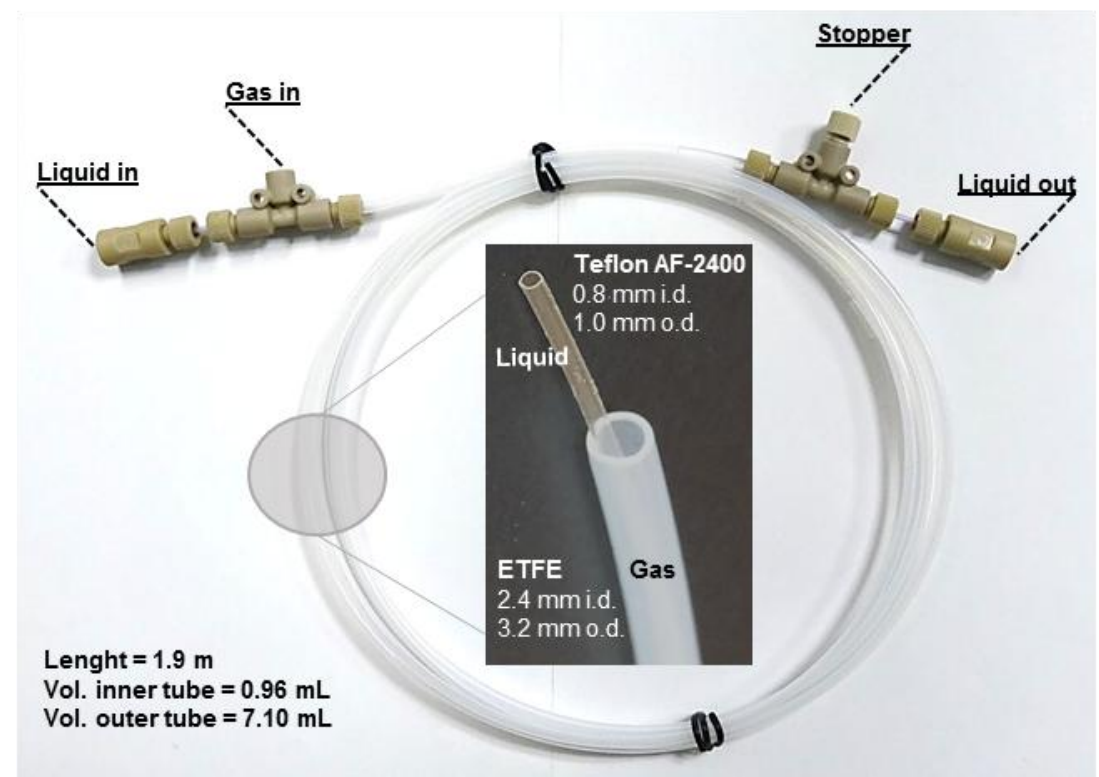

Figure 3. Photograph of the tube-in-tube device.

The ETFE tube was filled with oxidant gas at a pressure of either 1, 2 or 4 bar. At the reactor outlet, the T-piece is connected to an automatic 2-way-6-port switch valve which injects an aliquot of the reaction mixture into the HPLC line. The liquid stream was maintained at a constant pressure of 5 bar with an electronic back pressure regulator to avoid the formation of bubbles which disrupt the flow rate and modify the residence time. The volume occupied by the gas in the ETFE reactor is only $7.1 \mathrm{~mL}$ at any given time, considerably lowering the risks associated with the use of $\mathrm{O}_{2}$. An automated data processing integrates the chromatogram and calculates the yield using an internal standard ( $p$-xylene 7). A computer, running an ad-hoc process control software, controls the automated modules through RS-232 ports (represented by red dashed lines). Our initial studies were first conducted with $\mathrm{Co}^{\mathrm{II}}$ (salen) complex 8a which was previously identified as an efficient catalyst for related transformations. ${ }^{29,35-36}$ The results of our screening are depicted in Table 1. A rapid screening of the catalyst loading showed that working with $0.1,1$ or $5 \mathrm{~mol} \%$ of complex 8a at a residence time of 10 minutes and with 2 bar of $\mathrm{O}_{2}$ did not significantly affect the reaction outcome (Entries 4, 6, 11) while a sharp decrease of the reaction yield was observed when the catalyst loading was lowered to $0.05 \mathrm{~mol} \%$ (Entry 2). An uncatalyzed pathway was also observed since the background reaction conducted in the absence of 
complex 8a furnished carpanone 1 with $13 \%$ yield (Entry 1). Surprisingly, when the residence time was increased from 10 to 20 or even 30 minutes, the reaction yield marginally increased, reaching a maximum of $48 \%$ at $1 \mathrm{~mol} \%$ catalyst loading and 20 minutes of residence time (Entry 9). While this result cannot be fully rationalized, we hypothesized that it could be related to the rapid deactivation of the $\mathrm{Co}^{\mathrm{II}}$ (salen) complex $\mathbf{8} \mathbf{a}$ in the presence of oxygen into inactive and insoluble Co species. At high catalyst loadings ( $\geq 1 \mathrm{~mol} \%)$ the formation of insoluble particles was fast and were visually detected through the transparent tubing. The presence of insoluble Co species were attributed to the formation cobalt clusters which were favored at higher concentration. A related phenomenon was reported in palladium catalysis. ${ }^{37}$ A modulation of the pressure of oxygen provided interesting insights. A decrease of the pressure from 2 to 1 bar resulted in a sharp drop of the reaction yield from $43 \%$ to $9 \%$ (Entry 7) while, on the contrary, an increase of the pressure to 4 bar did not affect the reaction outcome (Entry 8). This result suggested that the mass transfer of $\mathrm{O}_{2}$ to the liquid stream at pressure $>2$ bar is not a limiting factor. Three other $\mathrm{Co}^{\mathrm{II}}$ complexes $(\mathbf{8 b}-\mathbf{d})$ were also evaluated, but without significant success (Entries 13-15). Interestingly, switching oxygen for air did not erode the reaction yield which reached a maximum of $47 \%$ at 20 min of residence time versus $48 \%$ with oxygen (Entries 16-17), corresponding to a space time yield of ca. 3.6 g.h $\mathrm{h}^{-1} \cdot \mathrm{L}^{-1}$. This result confirms that the oxidative dimerization of desmethoxycarpacine 6 to carpanone 1 with the tube-in-tube technology is neither governed by the mass transfer of gas to liquid nor by the formation of a radial gradient of gas with the highest concentration near the wall of the Teflon AF-2400 tubing. The modest reaction yields obtained with the tube-intube strategy was attributed to the tendency of Co complex 8a to aggregate into inactive species. We suspected that this behavior is accelerated by the absence of efficient mixing which was mainly governed by diffusion phenomenon.

Table 1. Oxidative dimerization of desmethoxycarpacine 6 to carpanone 1 using the tube-intube technology described in Figure 1.

\begin{tabular}{cccccc}
\hline Entry $^{a}$ & Oxidant & Catalyst & $\begin{array}{c}{[\mathrm{Co}] \text { loading }} \\
(\mathrm{mol} \%)\end{array}$ & $\begin{array}{c}\text { Residence } \\
\text { time }(\mathrm{min})\end{array}$ & Yield (\%) \\
\hline 1 & $\mathrm{O}_{2}$ & - & 0 & 10 & 13 \\
2 & $\mathrm{O}_{2}$ & {$[\mathrm{Co}]-\mathbf{8 a}$} & 0.05 & 10 & 27 \\
3 & $\mathrm{O}_{2}$ & {$[\mathrm{Co}]-\mathbf{8 a}$} & 0.05 & 20 & 31 \\
4 & $\mathrm{O}_{2}$ & {$[\mathrm{Co}]-\mathbf{8 a}$} & 0.1 & 10 & 40 \\
5 & $\mathrm{O}_{2}$ & {$[\mathrm{Co}]-\mathbf{8 a}$} & 0.1 & 20 & 42 \\
6 & $\mathrm{O}_{2}$ & {$[\mathrm{Co}]-\mathbf{8 a}$} & 1 & 10 & 42 \\
$7^{b}$ & $\mathrm{O}_{2}$ & {$[\mathrm{Co}]-\mathbf{8 a}$} & 1 & 10 & 9 \\
$8^{c}$ & $\mathrm{O}_{2}$ & {$[\mathrm{Co}]-\mathbf{8 a}$} & 1 & 10 & 43
\end{tabular}




\begin{tabular}{cccccc}
9 & $\mathrm{O}_{2}$ & {$[\mathrm{Co}]-\mathbf{8 a}$} & 1 & 20 & 48 \\
10 & $\mathrm{O}_{2}$ & {$[\mathrm{Co}]-\mathbf{8 a}$} & 1 & 30 & 47 \\
11 & $\mathrm{O}_{2}$ & {$[\mathrm{Co}]-\mathbf{8 a}$} & 5 & 10 & 38 \\
12 & $\mathrm{O}_{2}$ & {$[\mathrm{Co}]-8 \mathbf{a}$} & 5 & 20 & 43 \\
13 & $\mathrm{O}_{2}$ & {$[\mathrm{Co}]-8 \mathbf{b}$} & 1 & 10 & 12 \\
14 & $\mathrm{O}_{2}$ & {$[\mathrm{Co}]-8 \mathbf{c}$} & 1 & 10 & 36 \\
15 & $\mathrm{O}_{2}$ & {$[\mathrm{Co}]-8 d$} & 1 & 10 & 10 \\
16 & $\mathrm{Air}$ & {$[\mathrm{Co}]-8 \mathbf{a}$} & 1 & 10 & 46 \\
17 & $\mathrm{Air}$ & {$[\mathrm{Co}]-8 \mathbf{a}$} & 1 & 20 & 47 \\
18 & $\mathrm{Air}$ & - & 0 & 10 & 6 \\
$19^{\mathrm{b}}$ & $\mathrm{Air}$ & {$[\mathrm{Co}]-8 \mathbf{a}$} & 1 & 10 & 10 \\
\hline${ }^{a}$ Unless otherwise stated, the pressure of gas was fixed to 2 bar. ${ }^{b}$ The pressure of $\mathrm{O}_{2}$ was \\
fixed to 1 bar. ${ }^{c}$ The pressure of $\mathrm{O}_{2}$ was fixed to 4 bar.
\end{tabular}

One of the main limitations of the conventional tube-in-tube technology is the impossibility to conduct heated reactions because the flowing liquid is protected from the heat by a shell of gas. To circumvent this drawback, a reverse tube-in-tube configuration in which the liquid flows on the shell side and the gas is introduced through the inner Teflon AF-2400 tubing, has been occasionally reported. ${ }^{38-39}$ We envisioned the oxidative dimerization of desmethoxycarpacine 6 to caparnone 1 using the reverse tube-in-tube design. Unfortunately, in our preliminary experiments we faced an extensive diffusion phenomenon within the liquid stream which significantly increased the residence time compared to the normal tube-in-tube design at a given flow rate and strongly modified the reaction concentration as evidenced by the in-line UV monitoring. This unexpected behavior prompted us to give up on this strategy.

The automated tube-in-tube platform was reconfigurated for conducting gas-liquid segmented flow reactions (Figure 4). The tube-in-tube device was replaced by a single 1/8" ETFE tube $(7.8 \mathrm{~mL}, 1.72 \mathrm{~m}, 3.2 \mathrm{~mm}$ o.d., $2.4 \mathrm{~mm}$ i.d.) connected at the inlet to the liquid stream containing a mixture of desmethoxycarpacine $6(0.1 \mathrm{M})$ and $p$-xylene $7(1 \mathrm{M})$ in DCE and the gas inflow through a PEEK T-shaped junction with a stoichiometric molar ratio of $c a$. $3\left(\mathrm{O}_{2} /\right.$ desmethoxycarpacine 6). The gas stream was precisely delivered through the use of a mass flow controller. The reactor outlet was connected to an automatic 2-way-6-port switch valve which injected an aliquot of the reaction mixture into the HPLC line. The gas-liquid stream was maintained at a constant pressure of 4 bar with an electronic back pressure regulator. The use of a mass flow controller associated to the low volume of gas in the ETFE reactor, estimated to be below $6 \mathrm{~mL}$ at any given time, minimized the risks associated with the use of $\mathrm{O}_{2}$. The liquid handling robot which prepared the reaction mixtures, the heating chamber and the HPLC analysis system were connected to the computer through RS-232 
ports (red dashed lines) and controlled with MATLAB. Based on the previous results collected with the tube-in-tube system, we only considered the use of cobalt complex 8a to evaluate the gas-liquid segmented approach.

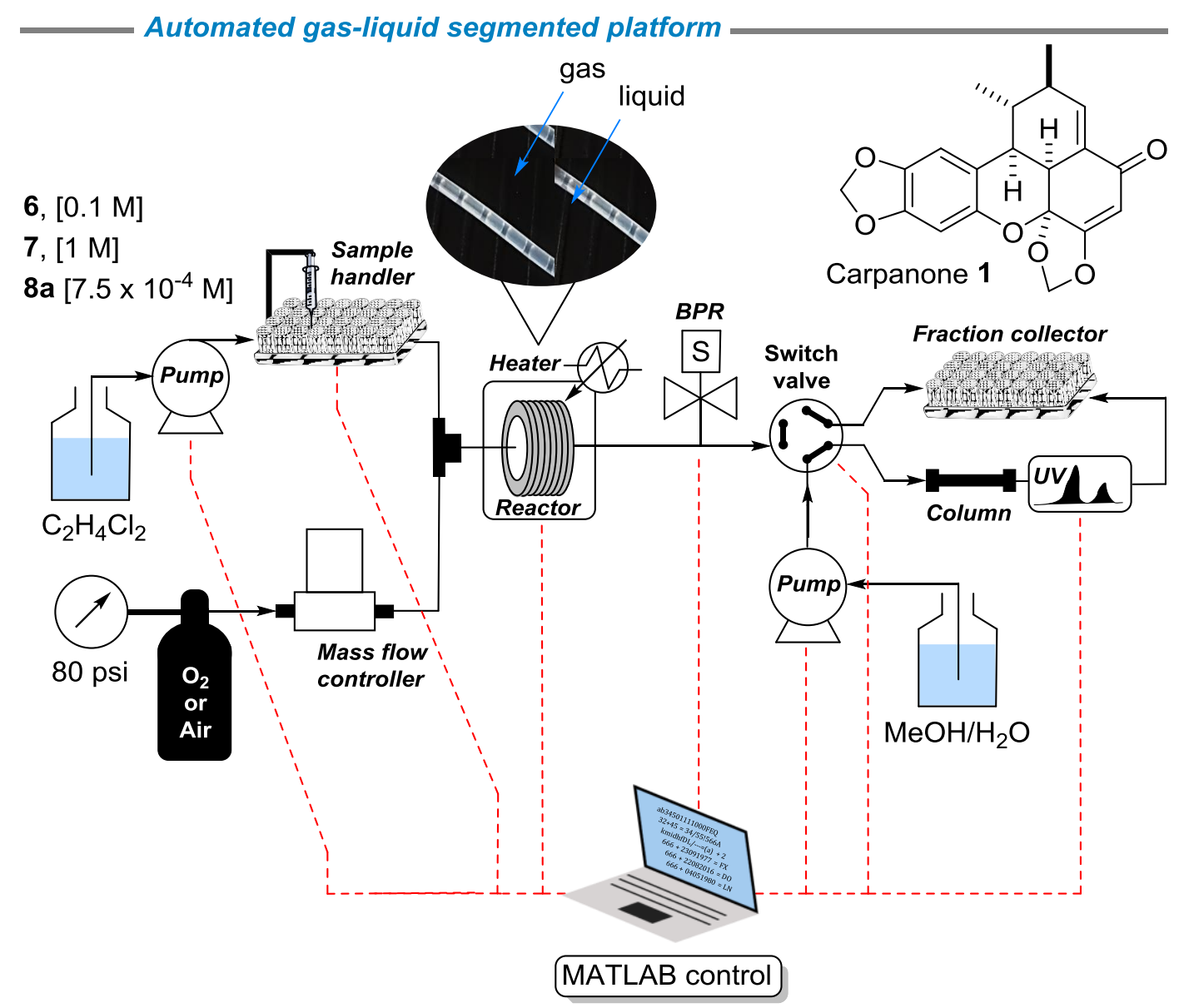

Figure 4. Automated gas-liquid segmented flow platform for the oxidative dimerization of desmethoxycarpacine $\mathbf{6}$ to carpanone $\mathbf{1}$.

Using $\mathrm{O}_{2}$ as oxidant, we evaluated the influence of the loading of complex 8a on the reaction yield for a given residence time of 10 minutes (Table 2). The reaction yield reached a plateau at $c a .62-65 \%$ with a loading of $\mathbf{8 a} \geq 1 \mathrm{~mol} \%$ (Entries 2-6), while the background reaction conducted in the absence of catalyst $8 \mathbf{a}$ marginally produced carpanone $\mathbf{1}$ (6\% yield, Entry 1). One advantage of the gas-liquid segmented system compared to the tube-in-tube device is the possibility to heat the reaction mixture. However, in our hand, the temperature increase from 25 to $45{ }^{\circ} \mathrm{C}$ was detrimental to the oxidative dimerization of desmethoxycarpacine 6 to carpanone 1. The high instability of both desmethoxycarpacine 6 and catalyst $8 \mathbf{a}$ under heating are likely responsible of this behavior. Similarly, an increase of the residence time 
from 10 to 20 minutes did not affect the reaction yield (Entry 9) while a decrease of the residence time to 5 minutes was not detrimental and furnished carpanone 1 with $62 \%$ yield, corresponding to a space time yield of $c a .4 .7 \mathrm{~g} \cdot \mathrm{h}^{-1} \cdot \mathrm{L}^{-1}$. Switching oxygen for air did not significantly modified the reaction outcome, though a higher catalyst loading $(2.5 \mathrm{~mol} \% \mathbf{8 a})$ and increased residence time (10 minutes) were required to reach the highest reaction yield (62\%, Entry 12). As already observed with the use of oxygen, any changes on experimental conditions failed to improve the reaction outcome since an increase of the temperature to 45 ${ }^{\circ} \mathrm{C}$ altered the yield (48\%, Entry 13) while an increase of the residence time to 20 minutes had no impact (Entry 15). These last results suggest that the catalytic cycle stops after ca. 5-10 minutes due to the high sensitivity of complex 8a which rapidly degrades under our experimental conditions.

While our automated screening platform is not suited for scale-up experiments, it can be used to prepare up to gram quantities through either higher volumes of injection (up to $2 \mathrm{~mL}$ per injection) or successive injections. For instance, we repeated 10 times the injection of $2 \mathrm{~mL}$ of the crude mixture from entry 8 to isolate after purification $464 \mathrm{mg}$ of carpanone 1 with an average yield of $61 \%$ (average over ten reactions).

Table 2. Oxidative dimerization of desmethoxycarpacine 6 to carpanone $\mathbf{1}$ with catalyst [Co]8a, using gas-liquid segmented approach.

\begin{tabular}{cccccc}
\hline Entry & Oxidant & $\begin{array}{c}{[\mathrm{Co}] \text { loading }} \\
(\mathrm{mol} \%)\end{array}$ & $\begin{array}{c}\text { Temperature } \\
\left({ }^{\circ} \mathrm{C}\right)\end{array}$ & $\begin{array}{c}\text { Residence } \\
\text { time }(\mathrm{min})\end{array}$ & Yield $(\%)$ \\
\hline 1 & $\mathrm{O}_{2}$ & 0 & 25 & 10 & 6 \\
2 & $\mathrm{O}_{2}$ & 0.1 & 25 & 10 & 42 \\
3 & $\mathrm{O}_{2}$ & 0.5 & 25 & 10 & 55 \\
4 & $\mathrm{O}_{2}$ & 1 & 25 & 10 & 62 \\
5 & $\mathrm{O}_{2}$ & 2.5 & 25 & 10 & 62 \\
6 & $\mathrm{O}_{2}$ & 5 & 25 & 10 & 65 \\
7 & $\mathrm{O}_{2}$ & 2.5 & 45 & 10 & 54 \\
8 & $\mathrm{O}_{2}$ & 1 & 25 & 5 & 62 \\
9 & $\mathrm{O}_{2}$ & 1 & 25 & 20 & 60 \\
10 & $\mathrm{Air}$ & 0 & 25 & 10 & 5 \\
11 & $\mathrm{Air}$ & 1 & 25 & 10 & 40 \\
12 & $\mathrm{Air}$ & 2.5 & 25 & 10 & 62 \\
13 & $\mathrm{Air}$ & 2.5 & 45 & 10 & 48 \\
14 & $\mathrm{Air}$ & 2.5 & 25 & 5 & 58 \\
15 & $\mathrm{Air}$ & 2.5 & 25 & 20 & 61 \\
\hline
\end{tabular}

From these studies we learnt a number of interesting features. Whatever the strategy used, tube-in-tube versus segmented flow, the gas to liquid mass transfer was not identified as the 
rate limiting factor. The high interfacial area per volume offered in flow reactors explained that the gas-liquid mass transfer was not the rate limiting step in our study. The switch of oxygen to air did not significantly affect the reaction outcome. This interesting feature could greatly facilitate the scaling-up as the use of air significantly mitigates the risks associated with such process. The gas-liquid segmented approach proved to be superior to the tube-intube system in terms of both yield (48vs. 62\%) and residence time (20vs. 5 minutes) for the oxidative dimerization of desmethoxycarpacine 6 to carpanone 1. While both approaches are of equivalent practicability, the gas-liquid segmented system was, in our hand, more robust than the tube-in-tube system toward the repetitive screening of experimental conditions. We were compelled to change the Teflon AF-2400 membrane $c a$. every two months of daily uses at pressure $\leq 4$ bar because upon prolonged exposure to DCE it became fragile and ripped. Moreover, Teflon AF-2400 tubing is a fragile perfluoropolymer which breaks upon folding, making tedious its handling. Another asset of the gas-liquid segmented approach is the selfmixing of liquid slugs due to the presence of vortices, also known as toroidal currents, which appear upon flowing despite a low Reynolds number of $c a$. 5. While the rate of oxidations with gas are often affected by the gas to liquid mass transfer, we identified with both systems the catalyst deactivation as the rate limiting step. The fast deactivation of complex 8a in the presence of oxygen and air bolsters our recent results showing the exceptional reactivity of $t$ $\mathrm{BuOOH}$ as oxygen-free surrogates for the cobalt-catalyzed dimerization of 3-propenylphenols into benzoxanthenones. ${ }^{30}$

\section{- CONCLUSION}

A reconfigurable automated flow platform has been designed for the cobalt-catalyzed oxidative dimerization of desmethoxycarpacine $\mathbf{6}$ to carpanone 1 with oxygen. The flow platform was used for the evaluation of two different approaches for the handling of molecular oxygen in flow. The traditional gas-liquid segmented strategy was compared to the original tube-in-tube system. We demonstrated that for both approaches, the gas to liquid mass transfer was not the rate limiting step of the cobalt-catalyzed oxidative dimerization and the catalyst deactivation was identified as a critical feature affecting the reaction yield. A careful assessment of both systems revealed that the gas-liquid segmented setup was more robust and allowed higher reaction yields than the tube-in-tube device which is penalized by the cost and fragility of the Teflon AF-2400 tubing. While we do not claim that the results compiled in this work can be generalized to any other oxidative process, they would serve to 
process chemists interested in the handling of oxygen in flow, far beyond the scope of the current study.

\section{— EXPERIMENTAL SECTION}

General information. All commercially available chemicals were used as received unless otherwise noted. ${ }^{1} \mathrm{H}$ and ${ }^{13} \mathrm{C}$ NMR spectra were recorded at 300 or 400 and $75 \mathrm{MHz}$ or 100 $\mathrm{MHz}$, respectively. ${ }^{1} \mathrm{H}$ and ${ }^{13} \mathrm{C}$ NMR spectra were referenced to the internal deuterated solvent $\left(\mathrm{CDCl}_{3}\right)$ at 7.26 and $77.16 \mathrm{ppm}$, respectively. FT-IR spectra were recorded in the ATR mode. Wavelengths of maximum absorbance $\left(v_{\max }\right)$ are quoted in wave numbers $\left(\mathrm{cm}^{-1}\right)$. High resolution mass spectrometry (HRMS) was recorded on a microTOF spectrometer equipped with orthogonal electrospray interface (ESI). Analytical thin-layer chromatography (TLC) was carried out on silica gel $60 \mathrm{~F}_{254}$ plates and visualized with a UV lamp at $254 \mathrm{~nm}$ or stained with a basic potassium permanganate solution. Flash column chromatography was performed using silica gel $60(40-63 \mu \mathrm{m})$. The AF-2400 permeable tubbing was purchased from Cambridge Reactor Design.

Details of the experimental setup. HPLC pumps (JASCO PU2080) equipped with a RS232 port were employed to flow the solution through the system. A sampler handler (JASCO AS 2055) equipped with a RS-232 port was used to inject the reagents in the line. The reactor coil was heated with a heating plate (Heidolph, MR Hei-Connect) equipped with a RS-232 port. The gas flow rate was controlled with a Brooks GF040 mass flow controller. A 2-way 6port valve (VICI, Cheminert C2-3006D) equipped with a RS-232 port was used to inject an aliquot of the crude mixture within the on-line HPLC unit. The HPLC column outlet was connected to a UV detector (JASCO, UV 2075) equipped with a RS-232 port. The flow outlet was connected to a programmable fraction collector (Advantec, CHF 1225C). All units equipped with a RS-232 port were autonomously controlled with MATLAB through the use of communication protocols provided by the manufacturers.

Synthesis of Carpanone 2 through the tube-in-tube approach. An automatic sample handler prepared $200 \mu \mathrm{L}$ of the reaction mixture from stock solutions of (E)-6-(prop-1-enyl)-1,3benzodioxol-5-ol $6^{29}(0.1 \mathrm{M}+p$-xylene 7 at $1 \mathrm{M})$ and [Co]-8a-d $\left(7.5 \times 10^{-4} \mathrm{M}\right)$. The reaction mixture was injected in a stream of $\mathrm{C}_{2} \mathrm{H}_{4} \mathrm{Cl}_{2}$ pumped at 0.096 and $0.048 \mathrm{~mL} / \mathrm{min}$ for 10 and 20 minutes residence time, respectively, as depicted in Figure 1. The liquid stream entered into the inner Teflon AF-2400 tubing (0.96 mL, $1.9 \mathrm{~m}, 1 \mathrm{~mm}$ o.d., $0.8 \mathrm{~mm}$ i.d.) of the tube-in- 
tube device. The liquid stream in the inner tube was subjected to a pressure of 5 bar using an electronic backpressure regulator while the outer ETFE tube $(7.1 \mathrm{~mL}, 1.9 \mathrm{~m}, 3.2 \mathrm{~mm}$ o.d., 2.4 mm i.d.) was subjected to 1, 2 or 4 bar of gas (oxygen or air) using a 2-stage regulator on the cylinder. The reactor outlet was connected to an automatic 2-way 6-port switch valve which injected $0.2 \mu \mathrm{L}$ of the crude mixture in the HPLC unit while the remaining stream was collected in a fraction collector. A mixture of $\mathrm{MeOH} / \mathrm{H}_{2} \mathrm{O}(70 / 30$, v/v) was used as mobile phase for the HPLC analysis at a flowrate of $0.4 \mathrm{~mL} / \mathrm{min}$. A UV detector was connected to the outlet of the HPLC column (Agela Promosil C18, $3.5 \mathrm{~mm} \times 150 \mathrm{~mm}, 5 \mu \mathrm{m}$ ) to follow the absorbance at a wavelength of $270 \mathrm{~nm}$. Peak integration and yield calculation were under full MATLAB automation.

Synthesis of Carpanone 2 through the gas-liquid segmented approach. An automatic sample handler prepared $200 \mu \mathrm{L}$ of the reaction mixture from stock solutions of $(E)$-6-(prop1-enyl)-1,3-benzodioxol-5-ol $6^{29}(0.1 \mathrm{M}+p$-xylene 7 at $1 \mathrm{M})$ and $[\mathrm{Co}]-8 \mathbf{a}\left(7.5 \times 10^{-4} \mathrm{M}\right)$. The reaction mixture was injected in a stream of $\mathrm{C}_{2} \mathrm{H}_{4} \mathrm{Cl}_{2}$ pumped at $0.38,0.19$ and $0.095 \mathrm{~mL} / \mathrm{min}$ for 5, 10 and 20 minutes residence time, respectively, as depicted in Figure 3. The liquid stream was connected through a PEEK T-shaped piece (internal volume: $0.57 \mu \mathrm{L}$ ) to a second stream flowing oxygen or air at a flow rate of 1.18, 0.59 and $0.295 \mathrm{~mL} / \mathrm{min}$ for 5,10 and 20 minutes residence time, respectively. The flow rate of the gas stream is controlled by a mass flow controller. The gas-liquid segmented stream entered in a 1/8" ETFE reactor coil $(7.8 \mathrm{~mL}$, $1.72 \mathrm{~m}, 3.2 \mathrm{~mm}$ o.d., $2.4 \mathrm{~mm}$ i.d.) thermostated at the required temperature. The reactor outlet was connected to an automatic 2-way 6-port switch valve which injected $0.2 \mu \mathrm{L}$ of the crude mixture in the HPLC unit while the remaining stream was collected in a fraction collector. The gas-liquid segmented flow was subjected to a pressure of 4 bar using an electronic backpressure regulator. A mixture of $\mathrm{MeOH} / \mathrm{H}_{2} \mathrm{O}(70 / 30$, v/v) was used as mobile phase for the HPLC analysis at a flowrate of $0.4 \mathrm{~mL} / \mathrm{min}$. A UV detector was connected to the outlet of the HPLC column (Agela Promosil C18, $3.5 \mathrm{~mm} \times 150 \mathrm{~mm}, 5 \mu \mathrm{m}$ ) to follow the absorbance at a wavelength of $270 \mathrm{~nm}$. Peak integration and yield calculation were under full MATLAB automation.

Analytical data for carpanone 1. mp 191-192 ${ }^{\circ} \mathrm{C}$ [Lit. $\left.{ }^{35} 189-190{ }^{\circ} \mathrm{C}\right]$. IR (ATR) $v 2872$, 1674, 1622, 1478, 1158, 1032, 910, $840 \mathrm{~cm}^{-1} .{ }^{1} \mathrm{H}$ NMR (300 MHz, $\left.\mathrm{CDCl}_{3}\right) \delta$ 7.01-7.03 (m, $1 \mathrm{H}), 6.80(\mathrm{~s}, 1 \mathrm{H}), 6.33(\mathrm{~s}, 1 \mathrm{H}), 5.91(\mathrm{~d}, 1 \mathrm{H}, J=1.3 \mathrm{~Hz}), 5.88(\mathrm{~d}, 1 \mathrm{H}, J=1.3 \mathrm{~Hz}), 5.69(\mathrm{~s}, 1 \mathrm{H})$, $5.67(\mathrm{~s}, 1 \mathrm{H}), 5.64(\mathrm{~s}, 1 \mathrm{H}), 3.27(\mathrm{dd}, 1 \mathrm{H}, J=2.3,7.4 \mathrm{~Hz}), 3.19(\mathrm{dt}, 1 \mathrm{H}, J=2.3,7.4 \mathrm{~Hz}), 2.52$ 
(br qd, 1H, $J=7.2 \mathrm{~Hz}$ ), 2.17-2.26 (m, 1H), 1.14 (d, 3H, $J=7.2 \mathrm{~Hz}), 0.71$ (d, 3H, $J=7.6 \mathrm{~Hz}$ ). ${ }^{13} \mathrm{C} \mathrm{NMR}\left(75 \mathrm{MHz}, \mathrm{CDCl}_{3}\right) \delta 187.0,168.5,146.8,145.3,143.3,142.7,126.4,115.4,107.2$, 101.4, 100.5, 100.3, 99.4, 98.9, 36.4, 35.6, 35.4, 33.7, 21.6, 21.3. HRMS (ESI) $\mathrm{m} / z[\mathrm{M}+\mathrm{H}]^{+}$ calcd for $\mathrm{C}_{20} \mathrm{H}_{19} \mathrm{O}_{6}, 355.1182$, found 355.1180 .

\section{ASSOCIATED CONTENT}

The supporting information is available free of charge on the ACS Publication website at DOI: 10.1021/acs.oprd.xxxxxxx

HPLC chromatograms; ${ }^{1} \mathrm{H}$ and ${ }^{13} \mathrm{C}$ NMR spectra of purified carpanone 2; photograph of the automated tube-in-tube system; photograph of the automated gas-liquid system; photograph of the gas-liquid segmented reactor (PDF)

\section{aUTHOR INFORMATION}

\section{Corresponding author}

*E-mail: fx.felpin@univ-nantes.fr

\section{ORCID}

François-Xavier Felpin: 0000-0002-8851-246X

\section{Notes}

The authors declare no competing financial interest.

\section{口 ACKNOWLEDGEMENTS}

We gratefully acknowledge the University of Nantes, the "Centre National de la Recherche Scientifique" (CNRS) and the "Région des Pays de la Loire" in the framework of the SmartCat project for financial support. E. C. Aka thanks the "Ministère de l'Enseignement Supérieur et de la Recherche Scientifique de Côte d'Ivoire" for a visiting grant in France. We acknowledge Julie Hémez (CEISAM, University of Nantes) for HRMS analyses.

\section{REFERENCES}

(1) Bäckvall, J.-E., Modern Oxidation Methods, 2nd Edition. Wiley-VCH: Weinheim, 2011; p 481. 
(2) Punniyamurthy, T.; Velusamy, S.; Iqbal, J., Recent Advances in Transition Metal Catalyzed Oxidation of Organic Substrates with Molecular Oxygen. Chem. Rev. 2005, 105, 2329-2364.

(3) Parmeggiani, C.; Cardona, F., Transition metal based catalysts in the aerobic oxidation of alcohols. Green Chem. 2012, 14, 547-564.

(4) Shi, Z.; Zhang, C.; Tang, C.; Jiao, N., Recent advances in transition-metal catalyzed reactions using molecular oxygen as the oxidant. Chem. Soc. Rev. 2012, 41, 3381-3430.

(5) Campbell, A. N.; Stahl, S. S., Overcoming the "Oxidant Problem": Strategies to Use O2 as the Oxidant in Organometallic $\mathrm{C}-\mathrm{H}$ Oxidation Reactions Catalyzed by $\mathrm{Pd}$ (and $\mathrm{Cu}$ ). Acc. Chem. Res. 2012, 45, 851-863.

(6) Osterberg, P. M.; Niemeier, J. K.; Welch, C. J.; Hawkins, J. M.; Martinelli, J. R.; Johnson, T. E.; Root, T. W.; Stahl, S. S., Experimental Limiting Oxygen Concentrations for Nine Organic Solvents at Temperatures and Pressures Relevant to Aerobic Oxidations in the Pharmaceutical Industry. Org. Process Res. Dev. 2015, 19, 1537-1543.

(7) Kurt, W. M.; Mitchell, A. Enhanced gas-liquid reactions. EP0439013 (A1), 1991.

(8) Hone, C. A.; Kappe, C. O., The Use of Molecular Oxygen for Liquid Phase Aerobic Oxidations in Continuous Flow. Top. Curr. Chem. 2018, 377, 2.

(9) Mallia, C. J.; Baxendale, I. R., The Use of Gases in Flow Synthesis. Org. Process Res. Dev. 2016, 20, 327-360.

(10) Gavriilidis, A.; Constantinou, A.; Hellgardt, K.; Hii, K. K.; Hutchings, G. J.; Brett, G. L.; Kuhn, S.; Marsden, S. P., Aerobic oxidations in flow: opportunities for the fine chemicals and pharmaceuticals industries. React. Chem. Eng. 2016, 1, 595-612.

(11) Gemoets, H. P. L.; Su, Y.; Shang, M.; Hessel, V.; Luque, R.; Noël, T., Liquid phase oxidation chemistry in continuous-flow microreactors. Chem. Soc. Rev. 2016, 45, 83-117.

(12) Gutmann, B.; Cantillo, D.; Kappe, C. O., Continuous-Flow Technology-A Tool for the Safe Manufacturing of Active Pharmaceutical Ingredients. Angew. Chem. Int. Ed. 2015, 54, 6688-6728.

(13) Hessel, V.; Kralisch, D.; Kockmann, N.; Noël, T.; Wang, Q., Novel Process Windows for Enabling, Accelerating, and Uplifting Flow Chemistry. ChemSusChem 2013, 6, 746-789.

(14) Leclerc, A.; Alamé, M.; Schweich, D.; Pouteau, P.; Delattre, C.; de Bellefon, C., Gasliquid selective oxidations with oxygen under explosive conditions in a micro-structured reactor. Lab Chip 2008, 8, 814-817. 
(15) Pieber, B.; Kappe, C. O., Direct aerobic oxidation of 2-benzylpyridines in a gas-liquid continuous-flow regime using propylene carbonate as a solvent. Green Chem. 2013, 15, 320324.

(16) Vanoye, L.; Aloui, A.; Pablos, M.; Philippe, R.; Percheron, A.; Favre-Réguillon, A.; de Bellefon, C., A Safe and Efficient Flow Oxidation of Aldehydes with O2. Org. Lett. 2013, 15, 5978-5981.

(17) Vanoye, L.; Pablos, M.; de Bellefon, C.; Favre-Réguillon, A., Gas-Liquid Segmented Flow Microfluidics for Screening Copper/TEMPO-Catalyzed Aerobic Oxidation of Primary Alcohols. Adv. Synth. Catal. 2015, 357, 739-746.

(18) Vanoye, L.; Wang, J.; Pablos, M.; Philippe, R.; Bellefon, C. d.; Favre-Réguillon, A., Continuous, Fast, and Safe Aerobic Oxidation of 2-Ethylhexanal: Pushing the Limits of the Simple Tube Reactor for a Gas/Liquid Reaction. Org. Process Res. Dev. 2016, 20, 90-94.

(19) Cherkasov, N.; Expósito, A. J.; Bai, Y.; Rebrov, E. V., Counting bubbles: precision process control of gas-liquid reactions in flow with an optical inline sensor. React. Chem. Eng. 2019, 4, 112-121.

(20) Aand, D.; Karekar, S.; Mahajan, B.; Pawar, A. B.; Singh, A. K., Controlled photo-flow oxidative reaction (UV-FOR) platform for ultra-fast phthalide and API synthesis. Green Chem. 2018, 20, 4584-4590.

(21) Feng, H.; Zhu, X.; Zhang, B.; Chen, R.; Liao, Q.; Ye, D.; Liu, J.; Liu, M.; Chen, G.; Wang, K., Visualization of two-phase reacting flow behavior in a gas-liquid-solid microreactor. React. Chem. Eng. 2019, 4, 715-723.

(22) Kumar, S.; Aand, D.; Pabbaraja, S.; Kim, D.-P.; Singh, A. K., Integrated Microfluidic Photo-Flow Process ( $\mu$-PFP) for Direct Upconversion of Exhaust Gas to Value-Added Chemicals. ACS Sustainable Chem. Eng. 2019, 7, 19605-19611.

(23) Yang, L.; Nieves-Remacha, M. J.; Jensen, K. F., Simulations and analysis of multiphase transport and reaction in segmented flow microreactors. Chem. Eng. Sci. 2017, 169, 106-116. (24) O’Brien, M.; Baxendale, I. R.; Ley, S. V., Flow Ozonolysis Using a Semipermeable Teflon AF-2400 Membrane To Effect Gas-Liquid Contact. Org. Lett. 2010, 12, 1596-1598.

(25) Brzozowski, M.; O’Brien, M.; Ley, S. V.; Polyzos, A., Flow Chemistry: Intelligent Processing of Gas-Liquid Transformations Using a Tube-in-Tube Reactor. Acc. Chem. Res. 2015, 48, 349-362.

(26) Petersen, T. P.; Polyzos, A.; O'Brien, M.; Ulven, T.; Baxendale, I. R.; Ley, S. V., The Oxygen-Mediated Synthesis of 1,3-Butadiynes in Continuous Flow: Using Teflon AF-2400 to Effect Gas/Liquid Contact. ChemSusChem 2012, 5, 274-277. 
(27) Bourne, S. L.; Ley, S. V., A Continuous Flow Solution to Achieving Efficient Aerobic Anti-Markovnikov Wacker Oxidation. Adv. Synth. Catal. 2013, 355, 1905-1910.

(28) Yang, L.; Jensen, K. F., Mass Transport and Reactions in the Tube-in-Tube Reactor. Org. Process Res. Dev. 2013, 17, 927-933.

(29) Cortés-Borda, D.; Wimmer, E.; Gouilleux, B.; Barré, E.; Oger, N.; Goulamaly, L.; Peault, L.; Charrier, B.; Truchet, C.; Giraudeau, P.; Rodriguez-Zubiri, M.; Le Grognec, E.; Felpin, F.-X., An Autonomous Self-Optimizing Flow Reactor for the Synthesis of Natural Product Carpanone. J. Org. Chem. 2018, 83, 14286-14299.

(30) Aka, E. C.; Wimmer, E.; Barré, E.; Vasudevan, N.; Cortés-Borda, D.; Ekou, T.; Ekou, L.; Rodriguez-Zubiri, M.; Felpin, F.-X., Reconfigurable Flow Platform for Automated Reagent Screening and Autonomous Optimization for Bioinspired Lignans Synthesis. J. Org. Chem. 2019, DOI: $10.1021 /$ acs.joc.9b02263.

(31) Chapman, O. L.; Engel, M. R.; Springer, J. P.; Clardy, J. C., Total Synthesis of Carpanone. J. Am. Chem. Soc. 1971, 93, 6696-6698.

(32) Baxendale, I. R.; Lee, A.-L.; Ley, S. V., A Concise Synthesis of Carpanone Using SolidSupported Reagents and Scavengers. J. Chem. Soc., Perkin Trans. 1 2002, 1850-1857.

(33) Daniels, R. N.; Fadeyi, O. O.; Lindsley, C. W., A New Catalytic Cu(II)/Sparteine Oxidant System for $\beta, \beta$-Phenolic Couplings of Styrenyl Phenols: Synthesis of Carpanone and Unnatural Analogs. Org. Lett. 2008, 10, 4097-4100.

(34) Liron, F.; Fontana, F.; Zirimwabagabo, J.-O.; Prestat, G.; Rajabi, J.; Rosa, C. L.; Poli, G., A New Cross-Coupling-Based Synthesis of Carpanone. Org. Lett. 2009, 11, 4378-4381.

(35) Constantin, M.-A.; Conrad, J.; Merişor, E.; Koschorreck, K.; Urlacher, V. B.; Beifuss, U., Oxidative Dimerization of (E)- and (Z)-2-Propenylsesamol with O2 in the Presence and Absence of Laccases and Other Catalysts: Selective Formation of Carpanones and Benzopyrans under Different Reaction Conditions. J. Org. Chem. 2012, 77, 4528-4543.

(36) Matsumoto, M.; Kuroda, K., Transition Metal(II) Schiff's Base Complexes Catalyzed Oxidation of trans-2-(1-propenyl)-4,5-methylenedioxyphenol to Carpanone by Molecular Oxygen. Tetrahedron Lett. 1981, 22, 4437-4440.

(37) Reetz, M. T.; de Vries, J. G., Ligand-free Heck reactions using low Pd-loading. Chem. Commun. 2004, 1559-1563.

(38) Mercadante, M. A.; Leadbeater, N. E., Continuous-flow, palladium-catalysed alkoxycarbonylation reactions using a prototype reactor in which it is possible to load gas and heat simultaneously. Org. Biomol. Chem. 2011, 9, 6575-6578. 
(39) Mercadante, M. A.; Kelly, C. B.; Lee, C.; Leadbeater, N. E., Continuous Flow Hydrogenation Using an On-Demand Gas Delivery Reactor. Org. Process Res. Dev. 2012, 16, 1064-1068. 